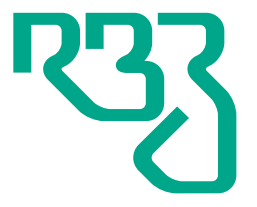

Revista

Brasileira de

Zootecnia

Brazilian Journal of Animal Science

ISSN 1806-9290

www.rbz.org.br

\title{
Environmental effects and repeatability of the follicular diameter in mares
}

\author{
Miguel Alejandro Silva Rua ${ }^{1}$ (iD), Celia Raquel Quirino ${ }^{1^{*}}$ (iD), Luis Fonseca \\ Matos $^{1}$ (iD), Ana Cláudia Cerqueira Rodrigues ${ }^{1}$ (iD , Aylton Bartholazzi Junior ${ }^{1}$ \\ ${ }^{1}$ Universidade Estadual do Norte Fluminense Darcy Ribeiro, Laboratório de Reprodução e \\ Melhoramento Genético Animal, Campos dos Goytacazes, RJ, Brasil.
}

*Corresponding author:
crqster@gmail.com

Received: February 22, 2019

Accepted: August 25, 2019

How to cite: Rua, M. A. S.; Quirino, C. R.; Matos,

L. F.; Rodrigues, A. C. C. and Bartholazzi Junior, A.

2019. Environmental effects and repeatability

of the follicular diameter in mares. Revista

Brasileira de Zootecnia 48:e20190047.

https://doi.org/10.1590/rbz4820190047

Copyright: This is an open access article

distributed under the terms of the

Creative Commons Attribution License

(http://creativecommons.org/licenses/by/4.0/) which permits unrestricted use, distribution, and reproduction in any medium, provided the original work is properly cited.

\begin{abstract}
The objective of this study was to evaluate the effect of environment on follicular diameter and repeatability of the size of preovulatory follicles of mares. Temperature, rainfall, and photoperiod were measured, and their effects were evaluated on follicular dynamics. Data were studied by analysis of variance of follicular size and environment traits. During the five years, 7\% double ovulations and 159 anovulatory follicles were recorded. Mean preovulatory follicle diameters of left and right ovaries were $39.3 \pm 3.8$ and $39.2 \pm 3.5 \mathrm{~mm}$ respectively. There was no effect of evaluation year on follicular diameter. Reproduction season affected the right preovulatory follicle diameter. There was no effect of temperature and rainfall on follicular diameter. Repeatability values of the preovulatory follicular diameter were low. In the subtropical climate studied, temperature and rainfall caused no effect on follicular dynamics, and photoperiod had only a small effect on dominant preovulatory follicular diameter. Repeatability of follicular diameter was low, so this characteristic should be evaluated daily to predict ovulation and the optimal time to inseminate mares.
\end{abstract}

Keywords: female, horse, reproduction

\section{Introduction}

The widespread use of reproductive biotechnologies for horse breeding is a reality and is increasing worldwide with the need to produce animals with superior genetics to compete in the market (Stroud and Callesen, 2012). With this need for breeding improvement, the use of semen of stallions with superior genetic traits is of great importance, and knowledge of the mare reproductive characteristics is necessary for good embryo recovery during a given breeding season.

Follicular dynamics and preovulatory diameter are essential characteristics to accurately predict the ovulation moment. This can be observed, but it takes lengthy evaluation time during the reproduction management in horse embryo transfer centers, in most cases making it unfeasible (Melo et al., 2012).

Therefore, the use of a standard to classify a follicle as preovulatory is an alternative to predict the most favorable moment to inseminate embryo donor mares. However, there are individual differences and effects of environment on reproductive characteristics, such as age of mare, year of observation, season, and climate. Therefore, evaluation of repeatability would be a useful tool to estimate if this characteristic tends to repeat over observations. Repeatability is a genetic parameter that can estimate the genotypic value of a trait that can be spread to other generations (Pereira, 2012). Therefore, this type of evaluation could help reproduction management of mares and improve breeding regarding the selection of donor mares (Sitzenstock et al., 2013). 
The objective of this study was to evaluate the preovulatory follicular diameter, daily growth of follicular diameter, and environmental factors that can influence the preovulatory follicular diameter and to estimate the repeatability of preovulatory follicle diameter of embryo donor mares in an embryo reproduction center.

\section{Material and Methods}

This experiment was performed with the approval of the local Committee on Ethical Use of Animals (CEUA) in accordance with the Brazilian Society of Laboratory Animal Science/Brazilian College of Animal Experimentation (SBCAL/COBEA) under case number 307.

A total of 195 embryo donor mares of the Mangalarga Marchador breed, aged from 10 to 23 years of age and with body condition from 7 to 8, were evaluated during five years - from 2012 to 2016. The mares were in an embryo transfer center located in northern Rio de Janeiro, Brazil (latitude: $21^{\circ} 45^{\prime} 15^{\prime \prime}$, longitude: $41^{\circ} 19^{\prime} 28^{\prime \prime}$, altitude: $13 \mathrm{~m}$ ). All mares were evaluated throughout the year, so they did not enter into seasonal anestrus in winter. They were evaluated in different reproductive seasons (RS). The period from October to April is considered the breading season (BS); May is considered the autumnal transition out of breeding season (ATBS); from June to August is considered the seasonal anestrus or non-breeding season (nBS); and September is considered the vernal transition into breeding season (VTBS) in the Brazilian tropical climate.

The animals were kept in an open shelter and outdoor paddock with access to pasture and supplemented twice a day with hay and $2.0 \mathrm{~kg}$ of pellet feed (Equitech, Brazil) containing $12 \%$ crude protein and 2,700 kcal of digestible energy, with amino acid supplementation of $25 \mathrm{~mL} /$ day (Glicopan Energy ${ }^{\circledR}$, Vetnil, São Paulo, Brazil). Trace-mineralized salt and water were available ad libitum.

The reproductive tract (uterus and ovaries) was examined by transrectal ultrasonography (Mindray ${ }^{\circledR}$ DP-2200 system, Shenzhen, China) with a 5-MHz linear transducer to determine the estrous cycle stage, presence and measurement of follicles, uterine edema, and intrauterine fluid. The evaluations were performed every day from the moment when a follicle having $30 \mathrm{~mm}$ diameter was detected. Each mare was evaluated repeatedly during the year.

During five years, the data on average monthly temperature and rainfall were collected, along with daily photoperiod, to calculate the respective reproductive seasonal averages.

The rainfall data were separated into classes, whereby 6 to $100 \mathrm{~mm}^{3}$ was considered "R1" and 101 to $200 \mathrm{~mm}^{3}$ was considered "R2". The same was done with average temperature, whereby 21 to $24{ }^{\circ} \mathrm{C}$ was considered "T1" and 24.1 to $28^{\circ} \mathrm{C}$ was considered "T2". Finally, the photoperiod was separated into two classes, one with 10:39 to 11:39 h of daylight, considered "P1", and the other with 11:40 to 13:18 h of daylight, considered "P2".

We evaluated the mean preovulatory follicle diameter one day before ovulation (D-1) and the daily growth from five days before ovulation (D-5) until the day of ovulation (D0). We also evaluated the effect of year of evaluation, RS, temperature, rainfall, and photoperiod on preovulatory follicular diameter (PFD). Finally, we calculated the repeatability of preovulatory follicle diameter.

Descriptive statistics were calculated from all collected data. The environmental effect (temperature, rainfall, and photoperiod) and follicular dynamics (dominant follicular diameter, daily dominant follicular growth, and preovulatory follicular diameter) were arranged in contingency tables and analyzed by the PROC MIXED routine, at 5\% probability of SAS (Statistical Analysis System, version 9.2).

The repeatability $(t)$ of preovulatory follicle diameter was calculated (by year and season) from the estimated variance (VAR) with the REML method of the VARCOM procedure of SAS. Repeatability of preovulatory follicular diameter was calculated using PROC VARCOMP-REML of SAS with:

$$
\mathrm{t}=\frac{\sigma_{\mathrm{B}}^{2}}{\sigma_{\mathrm{B}}^{2}+\sigma_{\mathrm{w}}^{2}}
$$

in which $\sigma_{\mathrm{B}}^{2}=$ variance among individuals and $\sigma_{\mathrm{w}}^{2}=$ variance within individuals. 


\section{Results}

The total number of ovulations was 2,124 during all years of evaluation. There were 1975 single ovulations (83\%) and 149 double ovulations (7\%), of them 38 in the right ovary (RO) and 45 in the left ovary (LO), plus 66 double ovulations, in which one dominant follicle grows in each ovary simultaneously and both follicles ovulate (from left and right ovaries). Finally, there were three triple ovulations, and during the five years, 159 anovulatory follicles were recorded.

The mean diameter of the preovulatory follicles (D-1) was similar in the left and right ovaries $(39.3 \pm 3.8$ and $39.2 \pm 3.5 \mathrm{~mm}$, respectively).

There was a progressive increase of follicle diameter until one day before ovulation. This increase was higher from day -4 to day -3 , with mean of $2.8 \mathrm{~mm}$ for dominant follicular growth, and growth decelerated from day -1 onward. Growth was similar in the left and right ovaries (Table 1).

Evaluating environmental effects (temperature, rainfall, and photoperiod) by month, we observed that there was difference on temperature and photoperiod $(\mathrm{P}<0.05)$; however, rainfall did not vary among months $(\mathrm{P}>0.05)$ (Table 2).

There was no difference in preovulatory follicular diameter among the years $(\mathrm{P}>0.05)$. The same result was observed in both ovaries (Table 3).

Regarding reproductive season, there was an effect only on the diameter of preovulatory follicle in the right ovary $(\mathrm{P}<0.05)$, with the highest mean recorded in the ATBS (Table 3 ).

There was no difference in preovulatory follicular diameter with different temperature (T1 and T2) and rainfall intervals (R1 and $\mathrm{R} 2)(\mathrm{P}>0.05)$ (Table 3).

Table 1 - Mean and standard deviation of follicular diameter $(\mathrm{mm})$ on days $(-5,-4,-3,-2$, and -1$)$ before ovulation

\begin{tabular}{lcccccc}
\hline Ovary & $\mathrm{N}$ & -5 & -4 & -3 & -2 & -1 \\
\hline Right & $(3050)$ & $30.8 \pm 4.7 \mathrm{a}$ & $32.8 \pm 4.1 \mathrm{a}$ & $35.6 \pm 4.0 \mathrm{a}$ & $37.9 \pm 3.6 \mathrm{a}$ & $39.3 \pm 3.8 \mathrm{a}$ \\
Left & $(2744)$ & $30.5 \pm 5.0 \mathrm{a}$ & $32.5 \pm 4.3 \mathrm{a}$ & $35.3 \pm 3.9 \mathrm{a}$ & $37.7 \pm 3.7 \mathrm{a}$ & $39.2 \pm 3.5 \mathrm{a}$ \\
DFG & & & $(5-4)$ & $(4-3)$ & $(3-2)$ & $(2-1)$ \\
Right & & & $2 \pm 0.6$ & $2.8 \pm 0.1$ & $2.3 \pm 0.4$ & $1.5 \pm 0.2$ \\
Left & & & $2 \pm 0.7$ & $2.8 \pm 0.4$ & $2.4 \pm 0.2$ & $1.5 \pm 0.2$ \\
\hline
\end{tabular}

$\mathrm{N}$ - number of observations; DFG - dominant follicular growth diameter (mm)

Means with a different superscript $(\mathrm{a}$ and $\mathrm{b})$ are different $(\mathrm{P}<0.05)$.

Table 2 - Means and standard deviations of environmental effects by month of evaluation

\begin{tabular}{lccc}
\hline \multirow{2}{*}{ Month of observation } & \multicolumn{3}{c}{ Environmental effect } \\
\cline { 2 - 4 } & Temperature & Rainfal & Photoperiod \\
\hline 1 & $27.2 \pm 1.0 \mathrm{a}$ & $94.7 .5 \pm 81.0 \mathrm{a}$ & $13.1 \pm 0.03 \mathrm{~b}$ \\
2 & $27.6 \pm 0.5 \mathrm{a}$ & $35.7 \pm 19.2 \mathrm{a}$ & $12.4 \pm 0.03 \mathrm{c}$ \\
3 & $27.0 \pm 0.6 \mathrm{a}$ & $128.8 \pm 53.6 \mathrm{a}$ & $12.1 \pm 0.3 \mathrm{~d}$ \\
4 & $25.7 \pm 1.0 \mathrm{bc}$ & $49.2 \pm 37.0 \mathrm{a}$ & $11.3 \pm 0.1 \mathrm{f}$ \\
5 & $23.2 \pm 0.6 \mathrm{fg}$ & $78.9 \pm 64.0 \mathrm{a}$ & $10.8 \pm 0.3 \mathrm{~h}$ \\
6 & $22.6 \pm 0.7 \mathrm{fg}$ & $46.5 \pm 29.1 \mathrm{a}$ & $10.4 \pm 0.01 \mathrm{j}$ \\
7 & $22.1 \pm 0.5 \mathrm{~g}$ & $68.1 \pm 65.2 \mathrm{a}$ & $10.6 \pm 0.2 \mathrm{i}$ \\
8 & $22.2 \pm 0.5 \mathrm{~g}$ & $39.7 .0 \pm 27.0 \mathrm{a}$ & $11.2 \pm 0.1 \mathrm{~g}$ \\
9 & $23.5 \pm 0.5 \mathrm{fe}$ & $40.2 \pm 30.3 \mathrm{a}$ & $11.8 \pm 0.3 \mathrm{e}$ \\
10 & $24.3 \pm 0.7 \mathrm{de}$ & $37.6 \pm 28.9 \mathrm{a}$ & $12.4 \pm 0.1 \mathrm{c}$ \\
11 & $25.0 \pm 0.9 \mathrm{~cd}$ & $123.2 \pm 48.2 \mathrm{a}$ & $13.1 \pm 0.1 \mathrm{~b}$ \\
12 & $26.7 \pm 1.2 \mathrm{ab}$ & $129.1 \pm 86.2 \mathrm{a}$ & $13.3 \pm 0.02 \mathrm{a}$ \\
\hline
\end{tabular}

a-j - Means with a different letter in the same column are different $(\mathrm{P}<0.05)$. 
Table 3 - Effect of year of evaluation, reproduction season, rainfall, and temperature on preovulatory follicular diameter $(\mathrm{mm})$

\begin{tabular}{|c|c|c|c|c|c|}
\hline \multirow{2}{*}{ Ovary } & \multicolumn{5}{|c|}{ Year of evaluation } \\
\hline & 2012 & 2013 & 2014 & 2015 & 2016 \\
\hline $\mathrm{N}$ & $(387)$ & (419) & (499) & $(131)$ & (283) \\
\hline Right & $39.4 \pm 3.2 \mathrm{a}$ & $39.4 \pm 4.4 \mathrm{a}$ & $39.4 \pm 3.4 \mathrm{a}$ & $39.1 \pm 3.7 \mathrm{a}$ & $39.3 \pm 4.0 \mathrm{a}$ \\
\hline Left & $39.5 \pm 3.7 \mathrm{a}$ & $39.5 \pm 3.7 a$ & $39.4 \pm 3.6 \mathrm{a}$ & $39.2 \pm 2.8 \mathrm{a}$ & $38.6 \pm 3.2 \mathrm{a}$ \\
\hline \multirow{2}{*}{ Ovary } & \multicolumn{5}{|c|}{ Reproduction season } \\
\hline & BS & \multicolumn{2}{|c|}{ ATBS } & nBS & VTBS \\
\hline $\mathrm{N}$ & $(899)$ & \multicolumn{2}{|c|}{$(142)$} & (531) & $(192)$ \\
\hline Right & $39.0 \pm 3.7 b$ & \multicolumn{2}{|c|}{$40.7 \pm 4.3 \mathrm{a}$} & $39.5 \pm 3.6 b$ & $39.4 \pm 3.8 b$ \\
\hline Left & $39.2 \pm 3.9 \mathrm{a}$ & \multicolumn{2}{|c|}{$39.2 \pm 3.2 \mathrm{a}$} & $39.1 \pm 2.9 \mathrm{a}$ & $39.3 \pm 3.4 \mathrm{a}$ \\
\hline \multirow{2}{*}{ Ovary } & & \multicolumn{2}{|c|}{ Temperature $\left({ }^{\circ} \mathrm{C}\right)$} & \multicolumn{2}{|c|}{ Rainfall $\left(\mathrm{mm}^{3}\right)$} \\
\hline & $\mathrm{N}$ & $\mathrm{T} 1$ & $\mathrm{~T} 2$ & $\mathrm{R} 1$ & $\mathrm{R} 2$ \\
\hline Right & $(792)$ & $39.4 \pm 3.9 a$ & $39.3 \pm 3.5 \mathrm{a}$ & $39.4 \pm 4.0 \mathrm{a}$ & $38.9 \pm 3.3 a$ \\
\hline Left & $(704)$ & $39.1 \pm 3.2 \mathrm{a}$ & $39.5 \pm 3.7 a$ & $39.3 \pm 3.4 \mathrm{a}$ & $39.3 \pm 3.6 \mathrm{a}$ \\
\hline \multirow{2}{*}{ Ovary } & \multicolumn{5}{|c|}{ Photoperiod } \\
\hline & $\mathrm{N}$ & \multicolumn{2}{|c|}{ P1 (h) } & \multicolumn{2}{|c|}{ P2 (h) } \\
\hline Right & $(824)$ & \multicolumn{2}{|c|}{$39.6 \pm 3.7 a$} & \multicolumn{2}{|c|}{$39.1 \pm 3.8 b$} \\
\hline Left & $(743)$ & \multicolumn{2}{|c|}{$39.2 \pm 3.0 \mathrm{a}$} & \multicolumn{2}{|c|}{$39.3 \pm 3.9 a$} \\
\hline
\end{tabular}

$\mathrm{N}$ - number of observations; BS - breeding season; ATBS - autumnal transition out of breeding season; nBS - non-breeding season; VTBS - vernal transition into breeding season; mean temperature ranging from 21 to $24^{\circ} \mathrm{C}$ (T1) and from 25 to $28^{\circ} \mathrm{C}$ (T2); rainfall ranging from 0 to $100 \mathrm{~mm}$ (R1) and from 101 to $235 \mathrm{~mm}^{3}$ (R2); day length from 10 to 11:40 h (P1) and from 11:41 to 13:18 h (P2).

$\mathrm{a}, \mathrm{b}$ - Means with a different letter are different $(\mathrm{P}<0.05)$

The photoperiod had an effect on preovulatory follicular diameter of the right ovary $(\mathrm{P}<0.05)$, with greater mean follicular diameter observed when daylight was shorter (P1). However, there was no effect of photoperiod on preovulatory follicular diameter of the left ovary $(\mathrm{P}>0.05)$ (Table 3$)$.

The estimated variance values for preovulatory follicle diameter were VAR (mare) $=0.042$ and VAR (residual + mare $)=0.587$, with the result of repeatability $t=0.07$. The estimated variance values for preovulatory follicle diameter were VAR (season) $=0.035$ and VAR (residual + season $)=0.280$, with result of repeatability $\mathrm{t}=0.11$.

\section{Discussion}

The rate of double ovulation of Mangalarga Marchador mares in this study was low and not significant for an embryo transfer program, because the rate $(7 \%)$ of double ovulation did not increase the embryo recovery rate considering all the ovulations during the evaluation period. Squires and McCue (2007) also reported that mares of breeds such as Thoroughbreds, Warmbloods, and Draft horses have higher rates of spontaneous double ovulation compared with others, so they have a greater embryo recovery rate per estrous cycle and are more productive in embryo transfer programs. Since double ovulation increases embryo production, the selection of Mangalarga Marchador donor mares with this natural trait can promote the genetic improvement of this breed for reproductive characteristics. It can thus be a criterion for selection of reproductive characteristics, as established in other countries such as Germany (Sitzenstock et al., 2013), associated with the morphofunctional traits that are already used for genetic improvement of horses (Andersson et al., 2012).

Knowledge of the pattern of follicular diameter variation can help make choices in embryo transfer programs by predicting the nearest moment to ovulation. It is unfeasible to evaluate ovulation by ultrasound of all mares during their cycles due the excessive time this would take. Mares are usually evaluated once a day or every other day, so we observed a pattern of daily follicular growth from day -5 until ovulation (Table 1). Another observation that can be a tool to predict ovulation is that as the 
moment of ovulation nears, the daily follicular growth decreases, indicating that ovulation is about to happen. Ginther et al. (2008) observed that follicles continue to grow at a steady rate until two days before ovulation, when follicular size reaches a plateau of approximately $40 \mathrm{~mm}$. This decreasing growth can be due to the peak production of inhibin near ovulation (Satué and Gordón, 2013).

Regarding the effect of year of evaluation, there was no influence $(P>0.05)$ on follicular dynamics of mares (Table 3). There were differences of temperature, rainfall, and quality/quantity of pasture, but none of those environmental effects caused changes in ovary traits in this study.

The RS defined in this study into four categories (BS, ATBS, nBS, and VTBS) can be used as a model in tropical regions of the southern hemisphere if climate and photoperiod do not have abrupt changes. The RS did not affect the follicular diameter in most evaluations (Table 3), except in ATBS, wherein the average preovulatory follicular diameter was slightly larger than other RS. This suggests that during this transitional phase, inadequate gonadotropin stimulation, mainly by LH with low circulating concentration, can act to delay ovulation, leading to a greater follicular growth until ovulation. Other authors have observed low concentration of LH in this phase, as well as no follicular diameter growth above $16 \mathrm{~mm}$ and no dominant follicle development (Donadeu and Watson, 2007; McKinnon et al., 2011). King et al. (2010) reported that the VTBS is characterized by the resumption of follicular deviation, with one to three anovulatory follicular waves before ovulation, and that during the winter (considered as the nBS), mares enter seasonal anestrous. In northern Rio de Janeiro state, mares continue cycling during the year, probably because the concentration of LH during transitional phases and nBS are sufficient to promote signals for final follicular development and ovulation (Table 3).

Environmental effects such as temperature and rainfall did not influence follicular dynamics (Table 3). This is probably because these two parameters do not have a sufficient variation to influence follicular dynamics, suggesting there are other factors that can affect the dominant follicular diameter. Warriach et al. (2014) reported that mares continue cycling throughout the year in subtropical regions even with lower temperatures than in the present study in winter or nBS. Higher temperatures and humidity during summer cause lower reproductive rates of mares, suggesting that the higher temperature can cause thermal stress, with negative effects on reproductive performance by stimulating release of corticotrophins and affecting the hypothalamus-hypophysis-gonad axis, decreasing the synthesis and release of gonadotropin FSH and LH (Kelley et al., 2011; Warriach et al., 2014). Even with the high summer temperatures, when the mares were evaluated in this study, they responded very well to hormonal treatment to induce ovulation, with small number of anovulatory follicles and usually one ovulatory wave. There was no superovulation protocol; then, multiple ovulation occurred naturally in the studied mares. These observations suggest that the mares studied are adapted to tropical climate, because Mangalarga Marchador is a Brazilian breed (Table 3).

Regarding the effect of photoperiod on follicular diameter (Table 3), we observed that the period when daylight hours was lowest (P1 - 10:39 to 11:39 h) corresponded to nBS and VTBS (winter and spring), and the mean follicular diameter (day -1) was bigger than in P2 (11:40 to 13:18 h of daylight), which corresponds to breeding season and ATBS (summer and autumn). According to Sharp (2011), mares raised in north America achieve seasonal anestrus during winter when daylight is lowed compared with summer. During periods with shorter daylight, the pineal gland is stimulated to synthesize and release more melatonin, and this hormone can suppress the hypothalamus, causing release of $\mathrm{GnRH}$; therefore, there is less stimulus on the hypophysis to release gonadotropin, mainly LH. Therefore, in winter and transitional phases, the concentrations of LH might not be sufficient to promote follicular development and ovulation of a dominant follicle. In the mares of this study, the photoperiod was not sufficient to interrupt ovulation, suggesting there were other factors favorable to ovary dynamics (McKinnon et al., 2011). The nutritional supplementation associated with good body condition of the mares (Aurich, 2011), climate (Oliveira et al., 2015), and genetic adaptations of the Mangalarga Marchador breed to this environment (Sitzenstock et al., 2013) are likely the factors causing mares to continue cycling year-round. However, the observation that the follicle diameter was bigger in shorter photoperiod can be explained by the fact that even though the hours of darkness were not sufficient to suppress follicular development, the dominant follicle spent more time to ovulate and, 
consequently, increased in size compared with what happened in the longer photoperiod, probably due to lower concentration of LH (McKinnon et al., 2011).

Regarding repeatability of the preovulatory follicle diameter during the five years of evaluation, we observed a low value of $t=0.07$, reflecting considerable variation and suggesting that follicle diameter cannot be expected to be the same one day before ovulation in every evaluation. When repeatability was calculated by season, we observed a result of $t=0.11$, also low. Lefrançois and Bruyas (2016) also observed low repeatability of the preovulatory follicular diameter in mares, and that knowledge of mare history regarding the diameter preceding ovulation would not be useful to estimate the best follicle diameter at which to breed the mare at the optimal time near ovulation. Furthermore, in this study, we evaluated the frequency of the diameter of the preovulatory follicle and observed that preovulatory follicle at 38 to $41 \mathrm{~mm}$ was the majority (58\%).

It is not possible to be certain that ovulation will occur on the day after observing a follicle with a specific diameter, but follicles at $38-41 \mathrm{~mm}$ do indicate that ovulation is near. Therefore, we can suggest that the low repeatability of follicular diameter indicates that the size of the preovulatory follicle is affected more by environmental factors than by mare genetics (Pereira, 2012).

\section{Conclusions}

In subtropical climates, photoperiod and temperature do not affect follicular dynamics. The low repeatability of the follicular diameter suggests that this characteristic must be evaluated daily when a follicle with diameter of $30 \mathrm{~mm}$ or larger is detected to predict the moment of ovulation and the optimal time to inseminate the mare.

\section{Conflict of Interest}

The authors declare no conflict of interest.

\section{Author Contributions}

Conceptualization: M.A.S. Rua. Data curation: M.A.S. Rua, C.R. Quirino, A.C.C. Rodrigues and A. Bartholazzi Junior. Formal analysis: M.A.S. Rua and C.R. Quirino. Investigation: M.A.S. Rua, C.R. Quirino, L.F. Matos and A. Bartholazzi Junior. Methodology: M.A.S. Rua and C.R. Quirino. Project administration: M.A.S. Rua and C.R. Quirino. Software: M.A.S. Rua. Supervision: M.A.S. Rua and C.R. Quirino. Validation: M.A.S. Rua. Writing-original draft: M.A.S. Rua and C.R. Quirino. Writing-review \& editing: M.A.S. Rua.

\section{Acknowledgments}

This work was conducted during a scholarship supported by Coordenação de Aperfeiçoamento de Pessoal de Nível Superior (CAPES).

\section{References}

Andersson, L. S.; Larhammar, M.; Memic, F.; Wootz, H.; Schwochow, D.; Rubin, C. J.; Patra, K.; Arnason, T.; Wellbring, L.; Hjalm, G.; Imsland, F.; Petersen, J. L.; McCue, M. E.; Mickelson, J. R.; Cothran, G.; Ahituv, N.; Roepstorff, L.; Mikko, S.; Vallstedt, A.; Lindgren, G.; Andersson, L. and Kullander, K. 2012. Mutations in DMRT3 affect locomotion in horses and spinal circuit function in mice. Nature 488:642-646. https://doi.org/10.1038/nature11399

Aurich, C. 2011. Reproductive cycles of horses. Animal Reproduction Science 124:220-228. https://doi.org/10.1016/j. anireprosci.2011.02.005

Donadeu, F. X. and Watson, E. D. 2007. Seasonal changes in ovarian activity: Lessons learnt from the horse. Animal Reproduction Science 100:225-242. https://doi.org/10.1016/j.anireprosci.2006.12.001

Ginther, O. J.; Gastal, E. L.; Gastal, M. O. and Beg, M. A. 2008. Dynamics of the equine preovulatory follicle and periovulatory hormones: What's new? Journal of Equine Veterinary Science 28:454-460. https://doi.org/10.1016/j.jevs.2008.07.008 
Kelley, D. E.; Gibbons, J. R.; Smith, R.; Vernon, K. L.; Pratt-Phillip, S. E. and Mortensen, C. J. 2011. Exercise affects both ovarian follicular dynamics and hormone concentrations in mares. Theriogenology 76:615-622. https://doi.org/10.1016/j. theriogenology.2011.03.014

King, S. S.; Douglas, B. L.; Roser, J. F.; Silvia, W. J. and Jones, K. L. 2010. Differential luteolytic function between the physiological breeding season, autumn transition and persistent winter cyclicity in the mare. Animal Reproduction Science 117:232-240. https://doi.org/10.1016/j.anireprosci.2009.04.012

Lefrançois, C. and Bruyas, J.-F. 2016. Is there a repeatability in the size of follicles at the time of ovulation within individuals in mares? Journal of Equine Veterinary Science 41:83. https://doi.org/10.1016/j.jevs.2016.04.086

McKinnon, A. O.; Squires, E. L.; Vaala, W. E. and Varner, D. D. 2011. Equine reproduction. 2nd ed, Vol. 1. Wiley-Blackwell, Ames.

Melo, C. M.; Papa, F. O.; Puoli Filho, J. N. P.; Araújo, G. H., Dell’Aqua Jr, J. A. and Alvarenga, M. A. 2012. Eficiência do acetato de deslorelina e do extrato de pituitária equina na indução da ovulação em éguas. Veterinária e Zootecnia 12:392-398.

Oliveira, J. P.; Jacob, J. C. F.; Jesus, V. L. T. and Silva, P. C. A. 2015. Influência da temperatura e umidade ambiente em um programa de transferência de embriões equinos, na Baixada Fluminense, Rio de Janeiro. Revista Brasileira de Medicina Veterinária 37:158-162.

Pereira, J. C. C. 2012. Melhoramento genético aplicado à produção animal. 6.ed. FEPMVZ, Belo Horizonte.

Satué, K. and Gardón, J. C. 2013. A Review of the estrous cycle and the neuroendocrine mechanisms in the mare. Journal of Steroids \& Hormonal Science 4:115. https://doi.org/10.4172/2157-7536.1000115

Sharp, D. C. 2011. Photoperiod. p.1771-1777. In: Equine reproduction. 2nd ed. McKinnon, A. O.; Squires, E. L.; Vaala, W. E. and Varner, D. D., eds. Wiley Blackwell, Philadelphia.

Sitzenstock, F.; Rathke, I.; Ytournel, F. and Simianer, H. 2013. The potential of embryo transfer in a German horse-breeding programme. Journal of Animal Breeding and Genetics 130:199-208. https://doi.org/10.1111/jbg.12003

Squires, E. L. and McCue, P. M. 2007. Superovulation in mares. Animal Reproduction Science 99:1-8. https://doi. org/10.1016/j.anireprosci.2006.04.054

Stroud, B. and Callesen, H. 2012. IETS statement on worldwide ET statistics for 2010. Animal Reproduction 9:210-216.

Warriach, H. M.; Memon, M. A.; Ahmad, N.; Norman, S. T.; Ghafar, A. and Arif, M. 2014. Reproductive performance of Arabian and Thoroughbred mares under subtropical conditions of Pakistan. Asian-Australasian Journal of Animal Sciences 27:932-936. https://doi.org/10.5713/ajas.2013.13547 